\title{
Treatment profiles and costs of patients with chronic pain in the population setting
}

This article was published in the following Dove Press journal:

ClinicoEconomics and Outcomes Research

25 January 2012

Number of times this article has been viewed

\author{
Antoni Sicras Mainar' \\ Ruth Navarro Artieda ${ }^{2}$ \\ Jesús Villoria Morillo 3 \\ Ana Esquivias Escobar ${ }^{4}$ \\ 'Dirección de Planificación, \\ Badalona Serveis Assistencials SA, \\ ${ }^{2}$ Documentación Médica, Hospital \\ Germans Trias i Pujol, Badalona, \\ Barcelona; ${ }^{3}$ Diseño y Redacción \\ Científica, Medicxact, Alpedrete, \\ ${ }^{4}$ Departamento Médico, Grünenthal \\ Pharma SA, Madrid, Spain
}

Background: The purpose of this study was to gather information about analgesic drug therapy in patients with chronic pain and perform cost estimates to guide future cost-effectiveness research in the area.

Methods: Data from patients aged 44 years and over suffering from any chronic condition and receiving regular analgesic drug therapy (for $\geq 6$ months) who attended health care facilities within the area of Badalona during 2008 were collected in a retrospective study. Morbidity profiles were defined according to treatment setting (pain unit, hospital), World Health Organization analgesic step (1-2 versus 3), and a raw cost model based on resource use and work absenteeism was applied. Patients attending the pain unit or the hospital were considered undertreated if they were on step 1-2 analgesics. Multiple regression was used to compare costs between undertreated and non-undertreated patients among those attending the pain unit or the hospital.

Results: Only 410 of 18,157 patients ascertained (2.3\%) were on step 3 analgesics. Their direct costs were greater than those of patients on step 1-2 analgesics, although the opposite was true regarding indirect costs. Of patients seen in the pain unit and in the hospital, $2.3 \%$ and $20.1 \%$, respectively, were considered undertreated. Regression analyses revealed even greater costs in the subgroup of undertreated patients.

Conclusion: Step 3 analgesics are barely used. Up to one-fifth of patients may be undertreated, generating greater costs than those considered to be properly treated. Regression analyses did not clarify the proportion of their cost excess that was attributable to undertreatment.

Keywords: pharmacoeconomics, analgesic treatment, observational studies, cost-effectiveness

\section{Introduction}

According to the International Association of the Study of Pain, pain can be defined as a disagreeable sensorial and emotional sensation associated with real or potential tissue damage. ${ }^{1}$ Its duration can be classified as acute or chronic, although it is sometimes difficult to distinguish between the two in clinical practice, because pain often has an oscillating presentation, sometimes with pain-free periods. ${ }^{2}$ Acute pain is of short duration, often has an identifiable cause, and responds well to analgesics. In contrast, chronic pain is often independent of the original cause, is usually more difficult to treat, and can itself be considered as an illness. Chronic pain is a public health problem worldwide..$^{3-5}$ Pain is a multidimensional problem influenced by biological, psychological, and social factors. Chronic pain will become more prevalent in the future, owing to increased life expectancy. Currently, the prevalence of chronic pain ranges from $10.1 \%$ to $55.2 \%$, depending on the population studied and the study design, although current evidence suggests that approximately $20 \%$ of the adult population
Correspondence: Antoni Sicras Mainar Dirección de Planificación y Desarrollo Organizativo, C Gaietà Soler, 6-8 entlo, 089II Badalona, Barcelona, Spain Tel +935072684

Email asicras@bsa.cat
(C) 2012 Mainar et al, publisher and licensee Dove Medical Press Ltd. This is an Open Access article which permits unrestricted noncommercial use, provided the original work is properly cited. 
(aged over 18 years) in developing countries suffers from chronic pain. ${ }^{6-10}$ Chronic pain can be considered as the third most important health problem in our setting, after cardiovascular disease and cancer, and has important economic repercussions, not only associated with medical, surgical and pharmaceutical costs, but also with work absenteeism, disability, and diminished quality of life. ${ }^{11-13}$

The World Health Organization analgesic ladder, based on the severity of pain (step 1, mild pain; step 2, moderate pain; and step 3, intense pain), reserves treatment with opiates for moderate-severe pain. ${ }^{14-16}$ This therapeutic approach has been shown to be very effective in treating cancer pain. However, the use of opiates for noncancer pain is controversial, because of concerns about their efficacy and safety, and the possibility of addiction. ${ }^{17,18}$ There is some evidence to suggest that chronic pain tends to go undertreated. Important contributing factors include: insufficient information about pain physiology; low sensitivity and specificity of the diagnosis; a lack of treatment guidelines reached by consensus; poor understanding of the medicinal products used, mainly of their mechanisms of action; reluctance to use certain pharmacological agents (especially opiates); and/or concern about the development of side effects, interactions, tolerance, or addiction (safety of the medication). ${ }^{19,20}$ In the light of this situation, more controlled clinical trials are required to establish a role for opiate therapy in the treatment of chronic pain and to identify criteria that can be used to select patients and treatment algorithms. This study is considered to be of relevance, owing to the insufficient epidemiological studies in patients with chronic pain and of the associated costs (economic analyses). This article presents the results of a retrospective observational study that compiled systematic sociosanitary, clinical, and health care data related to pain treatment in patients with chronic illnesses in an urban area of Spain. The aim was to determine patterns of analgesic drug therapy in routine clinical practice, the resources used, and the associated costs, with the aim of guiding future studies of cost-effectiveness and determining cost-related factors in the Spanish population with chronic pain.

\section{Materials and methods Design and study population}

A retrospective multicenter study was carried out by examining the medical records (computer databases) of patients followed in an outpatient setting and in hospital. The study population comprised patients from six primary care centers, ie, Apenins-Montigala, Morera-Pomar, Montgat-Tiana, Nova Lloreda, La Riera, and Marti-Julia, managed by Badalona
Serveis Assistencials SA. Information was obtained about the resources available in the two reference hospitals, ie, Hospital Municipal de Badalona and Hospital Germans Trías i Pujol (specialist care). The patients assigned to these centers mainly come from urban areas, have middle-low economic status, and mostly work in industry.

\section{Inclusion and exclusion criteria}

All patients attending the center for health care between January and December 2008 were recruited into the study if they presented with the following characteristics: age 45 years or older; diagnosed with an illness that had produced chronic pain for at least 6 months before the start of the study; inclusion in the program to receive chronic medical prescriptions (with records of the daily dose, time interval, and duration of each treatment administered); and use of more than five boxes of analgesics during the study period. Patients were excluded if they had been referred to other primary care centers, had died, or moved out of the area.

\section{Study groups in relation to use of analgesic medications}

Data about medicinal analgesic products were obtained from prescriptions of dispensed products collected from the pharmacies, according to the procedure for monitoring pharmaceutical prescriptions of CatSalut. Patients were selected if they regularly used nonopiate analgesics, nonsteroidal antiinflammatory drugs, or weak or strong opiates according to the Anatomical Therapeutic Chemical classification system. ${ }^{21}$ Finally, two study groups were established according to the World Health Organization analgesic ladder, ie, patients in step 1-2 (taking nonopiates and weak opiates), and patients in step 3 (treated with strong opiates). Details of the active ingredients of the drugs taken are shown in Table 1.

\section{Sociodemographic and comorbidity data}

The main study variables were: age (continuous and by intervals) and gender, and the patient's personal background obtained from the CIAP- $2^{22}$ component 7 of illness and health problems: arterial hypertension (K86, K87), diabetes mellitus (T89, T90), dyslipidemia (T93), obesity (T82), smoking (P17), alcoholism (P15, P16), all types of organ failure (cardiac, hepatic and renal), ischemic heart disease (K74, K76, K75), stroke (K90, K91, K93), chronic obstructive pulmonary disease (R95, chronic airway obstruction), bronchial asthma (R96), dementia or memory disorders (P70, P20), neurological diseases [Parkinson's disease (N87), epilepsy (N88), multiple sclerosis (N86) 
Table I Distribution of different active ingredients included in the study according to therapeutic groups and classification of the World Health organization analgesic ladder

\begin{tabular}{|c|c|c|c|c|c|c|}
\hline WHO ladder & ATC & Active ingredient & Boxes & $\%$ & RRP & $\%$ \\
\hline \multirow[t]{13}{*}{ Stage type I } & N02BEOI & Paracetamol & 67,211 & $37.8 \%$ & $204,215.94$ & $14.1 \%$ \\
\hline & MOIAEOI & Ibuprofen & 26,612 & $15.0 \%$ & $|26,0| 7.5 \mid$ & $8.7 \%$ \\
\hline & N02BB02 & Sodium metamizol & 9198 & $5.2 \%$ & $22,764.70$ & $1.6 \%$ \\
\hline & M0IAB05 & Diclofenac & 7715 & $4.3 \%$ & $21,905.62$ & $1.5 \%$ \\
\hline & MOIAEI7 & Dexketoprofen & 7498 & $4.2 \%$ & $50,342.20$ & $3.5 \%$ \\
\hline & M0IABI6 & Aceclofenac & 5864 & $3.3 \%$ & $46,906.17$ & $3.2 \%$ \\
\hline & MOIAE02 & Naproxen & 3303 & $1.9 \%$ & $21,230.60$ & $1.5 \%$ \\
\hline & N03AXI6 & Pregabalin & 3274 & $1.8 \%$ & $|92,73| .56$ & $13.3 \%$ \\
\hline & N03AXI2 & Gabapentin & 2947 & $1.7 \%$ & $|2|, 063.44$ & $8.3 \%$ \\
\hline & MOIABOI & Indomethacin & 2660 & $1.5 \%$ & 7347.14 & $0.5 \%$ \\
\hline & MOIAC06 & Meloxicam & 2494 & $1.4 \%$ & $17,595.79$ & $1.2 \%$ \\
\hline & MOIAHOI & Celecoxib & 1426 & $0.8 \%$ & $52,961.64$ & $3.6 \%$ \\
\hline & & Other (NSAID analgesics) & 8688 & $4.9 \%$ & $|25,4| 2.62$ & $8.6 \%$ \\
\hline \multirow[t]{5}{*}{ Stage type 2} & N02AX52 & Tramadol (combinations) & 9934 & $5.6 \%$ & $61,292.78$ & $4.2 \%$ \\
\hline & $\mathrm{N} 02 \mathrm{~A} \times 02$ & Tramadol & 8271 & $4.7 \%$ & $|5|, 6 \mid 5.23$ & $10.4 \%$ \\
\hline & N02BE5I & Paracetamol (combinations) & 3957 & $2.2 \%$ & 9600.97 & $0.7 \%$ \\
\hline & N02AA59 & Codeine (combinations) & 1690 & $1.0 \%$ & 4849.84 & $0.3 \%$ \\
\hline & N02BA5I & Acetyl salicylic acid (combined) & 646 & $0.4 \%$ & $1630.4 \mid$ & $0.1 \%$ \\
\hline \multirow[t]{5}{*}{ Stage type 3} & $\mathrm{~N} 02 \mathrm{AB} 03$ & Fentanyl & 2857 & $1.6 \%$ & $160,003.15$ & $11.0 \%$ \\
\hline & N02AE0I & Buprenorphine & 816 & $0.5 \%$ & $38,037.71$ & $2.6 \%$ \\
\hline & N02AA0I & Morphine & 586 & $0.3 \%$ & $10,176.38$ & $0.7 \%$ \\
\hline & N02AA05 & Oxycodone & 194 & $0.1 \%$ & 3524.15 & $0.2 \%$ \\
\hline & Total & & $|77,84|$ & $100.0 \%$ & $\mathrm{I}, 45 \mathrm{I}, 225.55$ & $100.0 \%$ \\
\hline
\end{tabular}

Abbreviations: WHO, World Health Organization; ATC, Guidelines for ATC classification; NSAID, nonsteroidal anti-inflammatory drug; RRP, recommended retail price.

and other neurological diseases (N99)]; and depressive syndrome (P76).

As a variable of general comorbidity for each patient attended in primary care, the Charlson Comorbidity Inde ${ }^{23}$ was used to give an approximation of the severity of the patient's condition, as well as the individual casuistic index, obtained from the adjusted clinical groups (ACG), and used to classify patients according to case-mix resource utilization. Mapping of the Clinical Information Access Portal was carried out according to international disease classification (ICD-9-CM). This was done by a working group comprising five experts (a documentalist, two clinicians, and two technical advisers). Different criteria were followed depending on whether no relationship (of one to none), a univocal relationship (of one to one), or a multiple relationship (from one to several) was established among the codes. The Grouper $\mathrm{ACG}^{\circledR}$ case-mix system algorithm comprises a series of consecutive steps to obtain 106 mutually exclusive ACG groups, one for each patient. ${ }^{24,25}$ The ACG procedure provides resource utilization bands, such that each patient can be grouped in relation to their overall comorbidity into one of five mutually exclusive categories, ie, healthy users or ones with a very low morbidity, low morbidity, moderate morbidity, high morbidity, and very high morbidity.

\section{Major morbidity categories}

Following the recommendations of the Spanish Pain Association (Sociedad Española del Dolor), patients were classified into four specific groups or categories: malignant neoplasms (this includes any type of malignant or suspected neoplasm); neuropathic pain (direct lesion of the nervous system, including painful mononeuropathies [posttraumatic, compressed nerve or radicular neuralgias], painful polyneuropathies, neuropathic pain by deafferentiation [eg, postherpetic neuralgia, amputation-induced neuromas, phantom limbs], and complex regional pain syndrome); musculoskeletal alterations (produced by dysfunction or pathology of components of the musculoskeletal system, including arthropathies [degenerative, inflammatory, crystalline deposits], alteration of soft tissues, bone diseases, and connective tissue disorders); and other chronic alterations. One patient could be included in several of these categories at the same time.

\section{Estimation of efficacy}

Given that there are no direct measures of efficacy, efficacy was estimated by considering five indicator measures, ie, treatment in a pain unit, specific analgesic treatment administered in a hospital, mean number of analgesics (nonopiate) 
per patient, and mean number of days of hospital stay per patient. Moreover, the patients treated in a hospital or pain unit were considered to be undertreated if they fulfilled either of the first two criteria but were not on stage 3 analgesics. In spite of the fact that this is a speculative definition, the authors consider that, in the absence of direct measures of efficacy, it can be considered to be accurate, particularly taking into account that a recent epidemiological study in Spain on the treatment of chronic noncancer pain reported that more than $60 \%$ of patients were on step 3 analgesia (personal communication). In the present study, we would expect this proportion to be even higher, considering that we also included cancer patients.

\section{Use of resources and models of costs}

Direct health costs were considered to be those related to health care activity (eg, medical visits, days of hospital stay, emergencies, orders of diagnostic/therapeutic tests) and carried out by health care professionals. Non-health care-related or indirect costs were those related to lost work productivity (number of absentees and days of absenteeism). The design of the cost system was defined by taking into account the characteristics of the organizations and the degree of development of the information systems available. The product unit upon which the final calculation was based during the study period was the one the patient attended and the cost was expressed as mean cost per patient (cost/unit). The different study concepts and their economic analyses are shown in detail in Table 2 (corresponding to data from 2008). The different fees were obtained from analytical accountancy data from each center, except for the cost of medication and days of absenteeism. Medical prescriptions (acute, chronic, or on demand) were

Table 2 Unit costs of health care resources and productivity losses from absenteeism

\begin{tabular}{ll}
\hline $\begin{array}{l}\text { Health care resources and non-health } \\
\text { resources }\end{array}$ & Unit costs (€) \\
\hline $\begin{array}{l}\text { Medical visits } \\
\quad \text { Visit to GP }\end{array}$ & 22.74 \\
Visit to emergency service & 115.23 \\
Hospitalization (one day) & $314.6 \mathrm{I}$ \\
Specialist medical care (referral) & 102.36 \\
Additional tests & \\
Laboratory tests & 21.86 \\
Conventional x-ray & 18.14 \\
$\quad$ Diagnostic/therapeutic tests & 36.45 \\
Pharmaceutical prescription & $\mathrm{RRP}$ \\
Work productivity & \\
$\quad$ Cost per day of absenteeism & 54.65 \\
\hline
\end{tabular}

Note: Source of health care data: authors' analytical accounts.

Abbreviations: GP, general practitioner; RRP, recommended retail price. quantified according to the recommended retail price per box at the time of prescription. Days of absenteeism or loss of productivity were considered as non-health care (indirect) costs. The cost was quantified in relation to the minimum interprofessional salary (sourced from Instituto Nacional de Estadística [INE]). In accordance with Spanish recommendations, the study protocol was approved by the Committee of Ethics of Clinical Research of the Foundation Gol and Gurina. All patients gave consent for their data to be used.

\section{Confidentiality of data and statistical analysis}

As a previous step to the analysis, especially before studying the information source corresponding to patients' computerized clinical records, the data were carefully checked, observing their frequency distributions and possible errors in their recording or encoding. The confidentiality of data was respected according to the Organic Law on Data Protection (15/1999, of December 13). A descriptive univariate statistical analysis was conducted with mean values, standard errors/ deviations, and confidence intervals (CI) of 95\%. The normality of the distribution was verified by the KolmogorovSmirnov test. For bivariate analysis, Student's $t$-test, analysis of variance, and Chi-square and Pearson's linear correlation tests were used. The corrected comparison of undertreated patients with the rest of the patients treated in the pain unit or hospital was conducted according to the recommendations of Thompson and Barber, ${ }^{26}$ by a multiple linear regression analysis (using a stepwise procedure, covariates of age and gender, and Charlson Comorbidity Index). A logistic regression was carried out to determine the association between comorbidities and use of strong opiates (enter procedure and Wald statistics). SPSSWIN software (v 17; SPSS Inc, Chicago, IL) was used to establish statistical significance at $P<0.05$.

\section{Results}

From an initial selection of 45,929 individuals aged over 44 years assigned to and regularly attending six centers, a total of 18,157 patients were selected. The estimated prevalence of patients taking regular treatment for chronic pain was 39.5\% (95\% CI: 39.1-39.9). By study group, 17,747 (97.7\%) patients were in step 1-2 of treatment and 410 (2.3\%) in step 3 $(P<0.001)$. The mean age of the patients was 66.2 years and $63.7 \%$ were women. The proportion taking opiate analgesia was $24.4 \%(n=4427,95 \%$ CI: $23.8-25.0)$.

Table 3 shows the general characteristics of the series, the associated comorbidities, and measures associated with the 
Table 3 General characteristics of the series studied and measures related to efficacy in analgesic stages

\begin{tabular}{|c|c|c|c|c|}
\hline $\begin{array}{l}\text { Study groups: analgesic step } \\
\text { subjects, } \%\end{array}$ & $\begin{array}{l}\text { Type I-2 } \\
\text { I7,747 (97.7\%) }\end{array}$ & $\begin{array}{l}\text { Type } 3 \\
410(2.3 \%)\end{array}$ & $\begin{array}{l}\text { Total } \\
\text { I8, } 157(100.0 \%)\end{array}$ & $P$ value \\
\hline \multicolumn{5}{|l|}{ Sociodemographic characteristics } \\
\hline Mean age, years & $66.1 \pm 11.3$ & $70.5 \pm 11.6$ & $66.2 \pm 11.3$ & $<0.001$ \\
\hline $45-54$ years & $17.7 \%$ & $11.2 \%$ & $17.5 \%$ & \\
\hline $55-64$ years & $29.5 \%$ & $19.3 \%$ & $29.3 \%$ & \\
\hline $65-74$ years & $26.8 \%$ & $28.0 \%$ & $26.8 \%$ & \\
\hline $75-84$ years & $20.7 \%$ & $31.2 \%$ & $21.0 \%$ & \\
\hline$>84$ years & $5.3 \%$ & $10.2 \%$ & $5.4 \%$ & $<0.001$ \\
\hline Gender (women) & $63.4 \%$ & $74.9 \%$ & $63.7 \%$ & $<0.00$ I \\
\hline \multicolumn{5}{|l|}{ General comorbidity } \\
\hline Mean RUB/patient & $3.0 \pm 0.6$ & $3.3 \pm 0.6$ & $3.0 \pm 0.6$ & $<0.001$ \\
\hline 1 & $2.2 \%$ & $0.0 \%$ & $2.2 \%$ & \\
\hline 2 & $10.5 \%$ & $4.1 \%$ & $10.4 \%$ & \\
\hline 3 & $75.0 \%$ & $66.3 \%$ & $74.8 \%$ & \\
\hline 4 & $10.7 \%$ & $23.9 \%$ & $11.0 \%$ & \\
\hline 5 & $1.5 \%$ & $5.6 \%$ & $1.6 \%$ & $<0.001$ \\
\hline Mean of episodes/patient & $7.6 \pm 3.9$ & $10.6 \pm 5.2$ & $7.7 \pm 3.9$ & $<0.001$ \\
\hline Mean Charlson index & $0.7 \pm 1.1$ & $1.3 \pm 1.4$ & $0.7 \pm 1.1$ & $<0.00$ I \\
\hline \multicolumn{5}{|l|}{ Associated comorbidities } \\
\hline Arterial hypertension & $50.6 \%$ & $63.9 \%$ & $50.9 \%$ & $<0.001$ \\
\hline Diabetes mellitus & $20.1 \%$ & $31.0 \%$ & $20.4 \%$ & $<0.001$ \\
\hline Dyslipemia & $45.3 \%$ & $44.5 \%$ & $45.2 \%$ & NS \\
\hline Obesity & $17.8 \%$ & $18.7 \%$ & $17.9 \%$ & NS \\
\hline Active smokers & $13.2 \%$ & $10.3 \%$ & $13.2 \%$ & NS \\
\hline Alcoholism & $2.0 \%$ & $1.5 \%$ & $1.9 \%$ & NS \\
\hline Ischemic heart disease & $8.4 \%$ & $14.0 \%$ & $8.5 \%$ & $<0.00$ I \\
\hline Stroke & $9.6 \%$ & $14.7 \%$ & $9.7 \%$ & $<0.00$ I \\
\hline Cardiovascular events & $16.4 \%$ & $27.3 \%$ & $16.7 \%$ & $<0.001$ \\
\hline Organic insufficiencies & $10.2 \%$ & $17.2 \%$ & $10.3 \%$ & $<0.00$ I \\
\hline Bronchial asthma & $5.1 \%$ & $7.1 \%$ & $5.1 \%$ & 0.039 \\
\hline COPD & $6.5 \%$ & $8.4 \%$ & $6.6 \%$ & NS \\
\hline Neuropathies & $1.1 \%$ & $2.9 \%$ & $1.1 \%$ & 0.002 \\
\hline Dementia (all types) & $2.0 \%$ & $2.5 \%$ & $2.0 \%$ & NS \\
\hline Depressive syndrome & $20.7 \%$ & $34.4 \%$ & $21.0 \%$ & $<0.001$ \\
\hline \multicolumn{5}{|l|}{ Major diagnostic categories } \\
\hline Cancer pain & $9.0 \%$ & $19.0 \%$ & $9.2 \%$ & $<0.001$ \\
\hline Neuropathic pain & $29.7 \%$ & $44.4 \%$ & $30.0 \%$ & $<0.001$ \\
\hline Musculoskeletal pain & $81.2 \%$ & $78.5 \%$ & $81.2 \%$ & NS \\
\hline Other alterations & $11.3 \%$ & $6.8 \%$ & $11.2 \%$ & 0.003 \\
\hline \multicolumn{5}{|l|}{ Measures related to efficacy } \\
\hline Patients visiting pain units & $2.0 \%$ & $18.3 \%$ & $2.4 \%$ & $<0.001$ \\
\hline Hospital admissions & $17.8 \%$ & $36.6 \%$ & $18.2 \%$ & $<0.001$ \\
\hline Mean of active ingredients/patient & $2.3 \pm 1.3$ & $4.5 \pm 1.4$ & $2.3 \pm 1.4$ & $<0.001$ \\
\hline Mean of opiates/patient & $0.2 \pm 0.4$ & $1.5 \pm 0.5$ & $0.3 \pm 0.5$ & $<0.001$ \\
\hline Mean of hospital stays/patient & $1.2 \pm 5.5$ & $2.0 \pm 8.5$ & $\mathrm{I} .4 \pm 6.4$ & $<0.001$ \\
\hline
\end{tabular}

Abbreviations: RUB, resource utilization bands; COPD, chronic obstructive pulmonary disease; NS, not statistically significant.

efficacy in relation to treatment type. The subjects treated with step 3 analgesia were of a higher mean age $(70.5$ years versus 66.1 years; $P<0.001)$, and a larger proportion of these were women (74.9\% versus $63.4 \% ; P<0.001)$. These subjects presented a greater overall comorbidity in episodes/patient ( 10.6 versus 7.6 ; $P<0.001)$ and Charlson index (1.3 versus $0.7 ; P<0.001)$.
In the corrected regression model, patients in step 3 presented a greater similarity in relation to cardiovascular events, odds ratio (OR): 1.9 (95\% CI: 1.1-3.3), depressive syndrome, OR: 1.8 (95\% CI: 1.5-2.3), female gender, OR: 1.7 (95\% CI: 1.3-2.1), and arterial hypertension, OR: 1.3 (95\% CI: 1.1-1.6, $P<0.031$ ). The intake of strong opiates 
was associated with cancer pain (OR: 1.6, 95\% CI: 1.3-2.0). An estimated $2.3 \%$ of patients received step 3 analgesics, representing $4.7 \%, 3.3 \%, 2.2 \%$, and $1.4 \%$ of patients with cancer pain, neuropathic pain, musculoskeletal pain, and pain of other origin, respectively.

The association between efficacy of treatment in the major diagnostic categories and study groups (analgesic treatment) is shown in Table 4. It is noteworthy that, using these indicators, on average $2.3 \%$ and $20.1 \%$ of patients did not receive adequate analgesia (undertreated) with step 1-2 analgesics when referred to the pain unit or admitted to hospital, respectively.

Table 5 shows the cost model (average/unit) of the series studied in the different analgesic steps. Patients taking step 3 analgesics required more resources, as recorded on the prescriptions for analgesics and greater direct health care costs. However, the indirect costs were lower in these patients. The total cost of health care in these patients amounted to EUR 50.1 million, of which $89.9 \%$ corresponded to direct health care costs and $10.1 \%$ to indirect health care costs.

Table 4 Relationship between efficacy (pain unit, hospital treatment) and major diagnostic categories relative to the study groups (analgesic treatment)

\begin{tabular}{|c|c|c|}
\hline $\begin{array}{l}\text { Characteristic } \\
\text { pain unit }\end{array}$ & $\begin{array}{l}\text { Present } \\
\mathrm{n}=439\end{array}$ & $\begin{array}{l}\text { Absent } \\
n=17,772\end{array}$ \\
\hline \multicolumn{3}{|l|}{ Step type I-2 (n, \%) } \\
\hline Cancer pain & $25(1.6)$ & I 577 (98.4) \\
\hline Neuropathic pain & $220(4.2)$ & $5058(95.8)$ \\
\hline Musculoskeletal pain & $308(2.2)$ & $14,155(97.9)$ \\
\hline Other alterations & $23(I . I)$ & $1990(98.9)$ \\
\hline Mean, \% & 2.3 & 97.7 \\
\hline \multicolumn{3}{|l|}{ Step type 3 (n, \%) } \\
\hline Cancer pain & $6(7.6)$ & $73(92.4)$ \\
\hline Neuropathic pain & $4 \mathrm{I}(22.4)$ & I 42 (77.6) \\
\hline Musculoskeletal pain & $63(19.3)$ & $263(80.7)$ \\
\hline Other alterations & $7(25.0)$ & $21(75.0)$ \\
\hline Mean, \% & 18.6 & 81.4 \\
\hline Hospital treatment & $n=3322$ & $n=14,889$ \\
\hline \multicolumn{3}{|l|}{ Step type I-2 (n, \%) } \\
\hline Cancer pain & $460(28.7)$ & II 42 (7I.3) \\
\hline Neuropathic pain & $915(17.3)$ & $4363(82.7)$ \\
\hline Musculoskeletal pain & 2565 (17.7) & II,898 (82.3) \\
\hline Other alterations & $332(16.5)$ & I68I (83.5) \\
\hline Mean, \% & 20.1 & 80.0 \\
\hline \multicolumn{3}{|l|}{ Step type $3(n, \%)$} \\
\hline Cancer pain & $34(43.0)$ & $45(57.0)$ \\
\hline Neuropathic pain & $49(26.8)$ & I34 (73.2) \\
\hline Musculoskeletal pain & $120(36.8)$ & $206(63.2)$ \\
\hline Other alterations & II (39.3) & $17(60.7)$ \\
\hline Mean, \% & 36.5 & 63.5 \\
\hline
\end{tabular}

The average/unit of total costs (health-related, non-healthrelated) in subjects on step 3 of the analgesic ladder was $€ 5764.1$ versus $€ 2686.9(P<0.001)$.

Multiple linear regression models adjusted for patients treated in the pain unit and in the hospital are shown in Table 6. Undertreatment was associated with an increase in total costs compared with patients on step 3 treatment. However, owing to the minimal contribution of the variables included in the adjusted analyses to the total variables, the increase in costs could have other causes not recorded here, such as the more complicated clinical conditions.

\section{Discussion}

In spite of the abundant information available on chronic pain, there are very few studies relating morbidity profiles to the treatments and resources utilized and the associated costs. This circumstance, together with the systematization of the database studied, makes this research of conceptual interest. The results suggest that step 3 analgesia is rarely used, and this is associated with an increase in direct costs. Nonetheless, without an appropriate standardization of the methodologies in relation to the patients' characteristics, and the number and measurement of the variables studied, the results obtained must be interpreted carefully and their external validity must be considered with caution. ${ }^{27}$ An important contribution of this work was adjustment of morbidity on the basis of a casemix resource utilization such as ACG. ${ }^{24,25}$

The general results of our study show a prevalence of patients receiving regular treatment for chronic pain of around $39.5 \%$, with a utilization of opiates in $24.4 \%$. In spite of the variability among the studies reviewed, these percentages are slightly higher than those reported in studies of the general population. ${ }^{6-9}$ This could be due to the fact that the patients studied in this work were aged over 44 years, and also due to the inclusion of patients with cancer pain. Nevertheless, the association of chronic pain with a larger proportion of osteoarticular problems (especially in the elderly, who have greater comorbidity), female gender, and mental illness, is similar to findings published previously., ${ }^{5,6}$ Regarding the analgesic regime in these patients, there appears to be an underutilization of step 3 analgesics, suggesting that many patients could be undertreated. There is also a clear underuse of opiates in most of the studies reviewed. ${ }^{16,17}$ Even doctors experienced at treating chronic pain show a reluctance to use opiates to treat severe noncancer pain. Our findings agree with those of Nicholson et al who suggest a need for doctors to receive better training in the use of opiates for analgesia. ${ }^{29}$ Inadequate pain relief can have important 
Table 5 Costs model (average/unit) of the series studied according to the different analgesic stages

\begin{tabular}{|c|c|c|c|c|}
\hline $\begin{array}{l}\text { Study groups } \\
\text { subjects, \% }\end{array}$ & $\begin{array}{l}\text { Type I-2 } \\
\text { I7,747 (97.7\%) }\end{array}$ & $\begin{array}{l}\text { Type } 3 \\
410(2.3 \%)\end{array}$ & $\begin{array}{l}\text { Total } \\
\text { I8, I57 (100.0\%) }\end{array}$ & $P$ value \\
\hline Cost in primary care & $1942.5 \pm 1294.9$ & $3719.6 \pm 2280.1$ & $1982.7 \pm 1351.2$ & $<0.001$ \\
\hline Visits to GP & $273.7 \pm 216.6$ & $459.5 \pm 301.8$ & $277.9 \pm 220.6$ & $<0.001$ \\
\hline Clinical tests & $121.9 \pm 97.2$ & $137.8 \pm 1 \mid 4.2$ & $122.3 \pm 97.6$ & $<0.001$ \\
\hline X-rays & $88.3 \pm 90.1$ & $103.3 \pm 103.5$ & $88.7 \pm 90.4$ & $<0.001$ \\
\hline Additional tests & $40.7 \pm 63.3$ & $60.9 \pm 91.2$ & $41.2 \pm 64.2$ & $<0.001$ \\
\hline Referral to specialists & $627.3 \pm 504.4$ & $992.7 \pm 896.7$ & $635.6 \pm 519.4$ & $<0.001$ \\
\hline Pharmaceutical prescription & $790.6 \pm 866.4$ & $1965.4 \pm 1566.9$ & $817.1 \pm 905.2$ & $<0.001$ \\
\hline Cost in specialist care & $464.9 \pm 1864.9$ & $1786.0 \pm 4255.3$ & $494.7 \pm 1961.0$ & $<0.001$ \\
\hline Hospital stay & $405.0 \pm 1834.8$ & $1649.0 \pm 4225.9$ & $433.1 \pm 1930.6$ & $<0.001$ \\
\hline Emergencies & $59.8 \pm 117.7$ & $137.0 \pm 202.6$ & $61.6 \pm 120.8$ & $<0.001$ \\
\hline Total health care costs & $2407.4 \pm 2436.2$ & $5505.6 \pm 5046.4$ & $2477.4 \pm 2566.5$ & $<0.001$ \\
\hline Non-health care costs (days absenteeism) & $279.5 \pm 1423.6$ & $258.5 \pm 1578.4$ & $279.0 \pm 1427.2$ & NS \\
\hline Total cost (health care and non-health care) & $2686.9 \pm 2794.3$ & $5764.1 \pm 5265.2$ & $2756.4 \pm 2909.5$ & $<0.001$ \\
\hline
\end{tabular}

Note: Values expressed in Euros.

Abbreviations: GP, general practitioner; NS, not significant.

depressive and emotional effects, causing suffering for patients and their relatives and also an increase in the use of health resources..$^{12,20}$

Since there is no direct measure of efficacy available, a patient was considered to be undertreated in a pain unit and/or when receiving analgesic treatment in a hospital if they did not receive any step 3 analgesics. This corresponded to $20.1 \%$ of patients in our study, and only $2.3 \%$ received strong opiates. It is difficult to draw comparisons with our results, although the use of strong opiates is similar to that

Table 6 Multiple linear regression model with association between variable undertreatment and costs

\begin{tabular}{|c|c|c|}
\hline Variables of equation & Coefficient & $95 \% \mathrm{Cl}$ \\
\hline \multicolumn{3}{|c|}{ Dependent: total costs $(€)\left[R^{2}=0.09\right]$} \\
\hline Constant* & 3507 & $2626-4386$ \\
\hline Age, years & 10 & $-3-23$ \\
\hline Gender, man versus woman & -148 & $-440-143$ \\
\hline Charlson index* & 975 & $868-1082$ \\
\hline Undertreatment (yes versus no) & 383 & $-69-836$ \\
\hline \multicolumn{3}{|c|}{ Dependent: total costs $(€)\left[R^{2}=0.09\right]$} \\
\hline Constant* & 4.07 & $3697-4442$ \\
\hline Age, years & -50 & $-55-44$ \\
\hline Gender, man versus woman & -196 & $-319-73$ \\
\hline Charlson index* & -29 & $-74-16$ \\
\hline Undertreatment (yes versus no) & -138 & $-329-54$ \\
\hline \multicolumn{3}{|c|}{ Dependent: total costs $(€)\left[R^{2}=0.15\right]$} \\
\hline Constant* & -563 & $-1365-239$ \\
\hline Age, years & 60 & $48-7 \mid$ \\
\hline Gender, man versus woman & 48 & $-218-314$ \\
\hline Charlson index* & 1,004 & $906-1101$ \\
\hline Undertreatment (yes versus no) & 521 & $109-934$ \\
\hline
\end{tabular}

Note: *Statistical significance (the confidence interval does not include 0 ).

Abbreviations: $\mathrm{Cl}$, confidence interval; $R^{2}$, coefficient of determination of the model. described in the literature. A review by Galvez ${ }^{30}$ describes how only $5 \%$ of patients in Europe received treatment with strong opiates, although there was some variability among countries. These percentages were higher $(11 \%-13 \%)$ in Ireland, the UK, and Denmark, whereas this was only $1 \%$ in Spain. Nonetheless, we must take into consideration that the use of opiates to treat chronic noncancer pain has not been well established, because there are still only a few systematic reviews and meta-analyses for this type of long-term pain. ${ }^{30-33}$ In clinical practice, treatment with opiates is conditioned by ethical, cultural, and legal considerations, because it can produce tolerance, adverse reactions, and physical dependence, leading to abstinence syndrome. ${ }^{19}$ However, effective treatment of pain and the control of side effects is an attainable goal in most patients with chronic pain. Latest reports support effective analgesia, especially in severe pain, where opiates play a more prominent role, particularly with controlled-release formulations of morphine, oxycodone, and transdermal patches of fentanyl and buprenorphine, which have less pronounced side effects. ${ }^{30}$ Patient response to these drugs may be variable, so treatment should be personalized. The mechanisms involved in irregular analgesic response and the appearance of side effects are not well known. Recently, a set of guidelines has been devised with the purpose of optimizing analgesic treatment with opiates. Briefly, these recommend adjusting the analgesic treatment to the intensity of pain, using the most appropriate route of administration for each patient, and monitoring the patient and dose with regular check-ups..$^{30,34}$

In the regression model, it is important to note that in routine clinical practice "undertreatment" was associated 
with costs even greater than in patients on step 3 of treatment. This could possibly be due to a selection bias, because the patients attended/selected who were being treated in the pain unit and/or hospital could, in general, present with more clinical complications than the others, and higher costs may be due largely to greater morbidity or severity. Nonetheless, since this comparison was made in the subgroup of patients treated in the pain unit or hospital, and, by definition, undertreated patients received step 3 analgesics (that have higher direct costs than the rest of the sample), this would suggest that the higher costs in the present study correspond to undertreated patients. A more appropriate, or better, treatment of these patients could reduce costs because an improvement in pain intensity, quality of life, or functionality would result directly in less use of health care resources. ${ }^{12,34,35}$

Possible limitations of this study lie in its limited geographical distribution, categorization of the disease (chronic pain), a possible bias in the classification of patients (analgesic step) and, especially, the lack of any direct measures of efficacy in the information system developed. Chronic pain conditions will most often possess many overlapping features between neuropathic, nociceptive, and even cancer pain syndromes. Categorizing chronic pain into distinct groupings may meet administrative requirements, but may not be functional in clinical practice. In addition, the World Health Organization ladder is based on subjective evaluation and a physician's clinical trial for the treatment of individual patients, so that could be considered by itself as a slightly objective parameter to assess the intensity of pain. In this study, we considered the World Health Organization analgesic ladder as a single indicator or isolated under treatment, as has always been taken into account in the quantitative administration of various drugs with the use of the expertise of pain. Therefore, this article reflects the limitations of the retrospective studies themselves; including an underrecording of the illness, its duration in time, or the possible doses of medication prescribed. Moreover, the variables that probably make an important contribution to establishing the costs present a clear dispersion among the regression models studied. In spite of these limitations, the results presented in this study still reflect a good approach to the pattern of use of analgesics in chronic pain. Future research must focus on cost/efficacy studies, for which direct measures of efficacy are required, and more controlled clinical trials to establish the role of opiate treatment in chronic pain of noncancer origin.

\section{Conclusion}

The results of this study indicate that step 3 analgesics are underused, since up to a fifth of patients may be undertreated and present greater associated direct costs. However, regression analysis did not identify the proportion of excess cost that was attributable to undertreatment.

\section{Acknowledgment/disclosure}

This study was financed by Grünenthal Pharma SA, which had no influence on the final results.

\section{References}

1. Breivik H. International Association for the Study of Pain: update on WHO-IASP activities. J Pain Symptom Manage. 2002;24:97-101.

2. Chung JW, Wong TK. Prevalence of pain in a community population. Pain Med. 2007;8:235-242.

3. Shahrbanian S, Ma X, Korner-Bitensky N, Simmonds MJ. Scientific evidence for the effectiveness of virtual reality for pain reduction in adults with acute or chronic pain. Stud Health Technol Inform. 2009; 144:40-43.

4. Provenzano DA, Fanciullo GJ, Jamison RN, McHugo GJ, Baird JC. Computer assessment and diagnostic classification of chronic pain patients. Pain Med. 2007;Suppl 3:S167-S175.

5. Cook AJ, Chastain DC. The classification of patients with chronic pain: age and sex differences. Pain Res Manag. 2001;6:142-151.

6. Catala E, Reig E, Artes M, Aliaga L, Lopez JS, Segu JL. Prevalence of pain in the Spanish population: telephone survey in 5000 homes. Eur J Pain. 2002;6:133-140.

7. Toth C, Lander J, Wiebe S. The prevalence and impact of chronic pain with neuropathic pain symptoms in the general population. Pain Med. 2009; 10:918-929.

8. Smith BH, Elliott AM, Chambers WA, Smith WC, Hannaford PC, Penny K. The impact of chronic pain in the community. Fam Pract. 2001;18:292-299

9. Thomas E, Peat G, Harris L, Wilkie R, Croft PR. The prevalence of pain and pain interference in a general population of older adults: crosssectional findings from the North Staffordshire Osteoarthritis Project (NorStOP). Pain. 2004;110:361-368.

10. Jones EA, McBeth J, Nicholl B, et al. What characterizes persons who do not report musculoskeletal pain? Results from a 4-year population-based longitudinal study (the Epifund study). J Rheumatol. 2009;36:1071-1077.

11. Vetter TR. The application of economic evaluation methods in the chronic pain medicine literature. Anesth Analg. 2007;105:114-118.

12. Turk DC. Chronic non-malignant pain patients and health economic consequences. Eur J Pain. 2002;6:353-355.

13. Thomsen AB, Sørensen J, Sjøgren P, Eriksen J. Economic evaluation of multidisciplinary pain management in chronic pain patients: a qualitative systematic review. J Pain Symptom Manage. 2001;22:688-698.

14. Azevedo São Leão Ferreira K, Kimura M, Jacobsen Teixeira M. The WHO analgesic ladder for cancer pain control, twenty years of use. How much pain relief does one get from using it? Support Care Cancer. 2006;14:1086-1093.

15. Ventafridda V, Saita L, Ripamonti C, De Conno F. WHO guidelines for the use of analgesics in cancer pain. Int J Tissue React. 1985; 7:93-96.

16. Trescot AM, Glaser SE, Hansen H, Benyamin R, Patel S, Manchikanti L. Effectiveness of opioids in the treatment of chronic non-cancer pain. Pain Physician. 2008;11(Suppl 2):S181-S200.

17. Moore RA, McQuay HJ. Prevalence of opioid adverse events in chronic non-malignant pain: systematic review of randomised trials of oral opioids. Arthritis Res Ther. 2005;7:R1046-R1051. 
18. McNicol E, Horowicz-Mehler N, Fisk RA, et al; Americal Pain Society. Management of opioid side effects in cancer-related and chronic noncancer pain: a systematic review. J Pain. 2003;4:231-256.

19. Fishbain DA, Cole B, Lewis J, Rosomoff HL, Rosomoff RS. What percentage of chronic nonmalignant pain patients exposed to chronic opioid analgesic therapy develop abuse/addiction and/or aberrant drugrelated behaviors? A structured evidence-based review. Pain Med. 2008;9:444-459.

20. Porreca F, Ossipov MH. Nausea and vomiting side effects with opioid analgesics during treatment of chronic pain: mechanisms, implications, and management options. Pain Med. 2009;10:654-662.

21. Guidelines for ATC classification. Oslo, Norway: Nordic Collaborating Centre for Drug Statistics Methodology; 1991.

22. Lamberts H, Wood M, Hofmans-Okkes IM, editors. The International Classification of Primary Care in the European Community with a Multi-Language Layer. Oxford, UK: Oxford University Press; 1993.

23. Charlson ME, Pompei P, Ales KL, Mackenzie CR. A new method of classifying prognostic comorbidity in longitudinal studies: development and validation. J Chronic Dis. 1987;40:373-383.

24. Weiner JP, Starfield BH, Steinwachs DM, Mumford LM. Development and application of a population-oriented measure of ambulatory care case-mix. Med Care. 1991;29:452-472.

25. The Johns Hopkins ACG ${ }^{\mathbb{R}}$ Case-Mix System, version 7.0 April, 2005. Baltimore, MD: Johns Hopkins Bloomberg School of Public Health; 2005.

26. Thompson SG, Barber JA. How should cost data in pragmatic randomised trials be analysed? BMJ. 2000;320:1197-1200.
27. Sackett D, Rosenberg W, Gray J, Haynes RB. Richardson WS: Evidencebased medicine: what it is and what it isn't. BMJ. 1996;312:71-72.

28. Morley-Forster PK, Clark AJ, Speechley M, Moulin DE. Attitudes toward opioid use for chronic pain: A Canadian physician survey. Pain Res Manag. 2003;8:189-194.

29. Nicholson B. Responsible prescribing of opioids for the management of chronic pain. Drugs. 2003;63:17-32.

30. Galvez R. Variable use of opioid pharmacotherapy for chronic noncancer pain in Europe: causes and consequences. J Pain Palliat Care Pharmacother. 2009;23:346-356.

31. Rodriguez MJ. Survey of therapeutic attitudes towards patients with chronic pain in Spanish Pain Units. Rev Soc Esp Dolor. 2006;8: 525-532.

32. Rowbotham MC, Lindsey CD. How effective is long-term opioid therapy for chronic noncancer pain? Clin J Pain. 2007;23:300-302.

33. Kalso E, Edwards JE, Moore RA, McQuay HJ. Opioids in chronic non-cancer pain: systematic review of efficacy and safety. Pain. 2004; 112:372-380.

34. Rauck RL. What is the case for prescribing long-acting opioids over short-acting opioids for patients with chronic pain? A critical review. Pain Pract. 2009;9:468-479.

35. van Leeuwen MT, Blyth FM, March LM, Nicholas MK, Cousins MJ. Chronic pain and reduced work effectiveness: the hidden cost to Australian employers. Eur J Pain. 2006;10:161-166.
ClinicoEconomics and Outcomes Research

\section{Publish your work in this journal}

ClinicoEconomics \& Outcomes Research is an international, peerreviewed open-access journal focusing on Health Technology Assessment, Pharmacoeconomics and Outcomes Research in the areas of diagnosis, medical devices, and clinical, surgical and pharmacological intervention. The economic impact of health policy and health systems

\section{Dovepress}

organization also constitute important areas of coverage. The manuscript management system is completely online and includes a very quick and fair peer-review system, which is all easy to use. Visit http://www.dovepress.com/testimonials.php to read real quotes from published authors. 